Johanna M. Singer

\title{
Arme adlige Frauen im Deutschen Kaiserreich
}

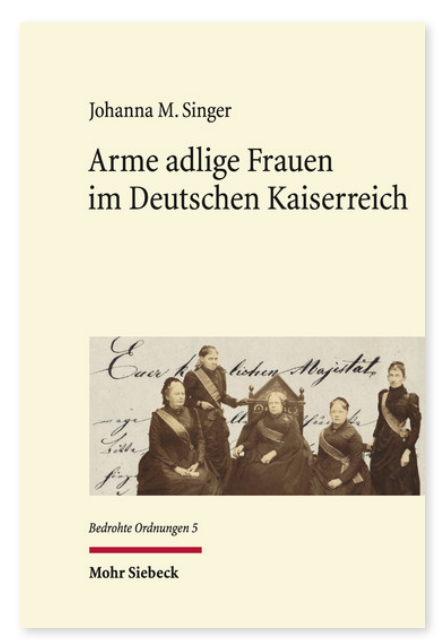

2016. XIV, 452 Seiten. BedrO 5

ISBN 978-3-16-154381-4 DOI 10.1628/978-3-16-154381-4 eBook PDF 99,00€

ISBN 978-3-16-154380-7

Festeinband $99,00 €$
Adel und Armut - diese beiden Begriffe scheinen nicht zusammenzupassen. Wer an Adel in der Zeit des Kaiserreichs denkt, assoziiert zumeist Schlösser, weitläufigen Landbesitz, rauschende Bälle, auf denen elegante Damen in prächtigen Kleidern mit schneidigen Gardeoffizieren tanzen. Der Adel gilt als Elite- und zwar besonders für die Zeit vor 1914, die im Rückblick oft gleichsam als seine letzte Blütezeit erscheint. Dabei handelt es sich aber um ein unvollständiges Bild adliger Lebenswirklichkeiten im 19. und frühen 20. Jahrhundert. Johanna M. Singer zeigt einen anderen Teil der Geschichte des Adels im Kaiserreich, einen Teil, der wenig bekannt ist, der fernab von mondänem Lebensstil und politischem Einfluss stattfand und der den scheinbar so offensichtlichen Zusammenhang von Adel und Elite konterkariert. Er führt uns in die Welt adliger Frauen, die in kleinen Etagenwohnungen lebten, sich kein Dienstpersonal leisten konnten, sondern vielmehr selbst 'in Stellung gehen' mussten. Armut im Adel war in der Zeit um 1900 eine soziale Realität, die insbesondere ledige Frauen und Witwen betraf. Ihre Geschichte wurde bisher noch nicht geschrieben. Die Autorin geht Ursachen, Ausprägungen und Bewältigungsstrategien weiblicher Armut im Adel nach und fragt nicht zuletzt danach, wie die Frauen selbst und ihre Familien, aber auch Standesgenossen und staatliche Stellen mit diesem Phänomen umgingen.

Johanna M. Singer Geboren 1985; 2004-11 Studium der Fächer Geschichte, Politikwissenschaft und Spanisch; 2010 Staatsexamen Geschichte/Politkwissenschaft; 2011 Staatsexamen Spanisch; 2011-15 Wissenschaftliche Mitarbeiterin am Sonderforschungsbereich 923 »Bedrohte Ordnungen« an der Universität Tübingen; 2015 Abschluss der Dissertation.
Jetzt bestellen:

https://mohrsiebeck.com/buch/arme-adlige-frauen-im-deutschen-kaiserreich-9783161543814?no_cache=1 order@mohrsiebeck.com

Telefon: +49 (0)7071-923-17

Telefax: $+49(0) 7071-51104$ 